\title{
Dynamic regulation of macrophage polarization via coupled multicellular networks
}

\author{
Yishan Chuang*, Joshua N Leonard \\ From Society for Immunotherapy of Cancer 28th Annual Meeting \\ National Harbor, MD, USA. 8-10 November 2013
}

Macrophages functionally polarize towards either immunostimulatory (M1) or immunosuppressive (M2) phenotypes, and tumor-associated macrophages (TAMs) exhibit an M2-like phenotype that impedes immunotherapy. Although the importance of M2 cells in tumor progression is well established, the process by which macrophages "decide" to adopt an M2 phenotype in complex environments is not well understood and is the subject of this study. Most prior investigations have applied "coherent" stimuli (exclusively pro-M1 or pro-M2 signals), yet these stimuli rarely exist independently in vivo. To understand how macrophages integrate incoherent stimuli (both proM1 and pro-M2 simultaneously), we first exposed macrophages to dosed combinations of IL-10 and IL-12. Contrary to reports that IL-12 directly alters macrophage polarization state, we observed that when competing directly with IL-10, IL-12 had little direct effect on macrophage polarization. Instead, our data suggest that maintenance of the IL-10-induced M2 state is mediated via the $\mathrm{NF} \kappa \mathrm{B}$ inhibitor BCL-3, and the M2 state was disrupted by either removal of IL-10 or co-treatment with the pro-M1 stimulus IFN $\gamma$. Together, these data suggest that IL-12 may indirectly promote $\mathrm{M} 1$ phenotypes by inducing innate and adaptive immune cells to produce IFN $\gamma$ in the tumor microenvironment. To investigate how interactions between macrophages may influence polarization outcomes, we next examined polarization in individual cells using flow cytometry. Surprisingly, we observed that M1 and M2 cells co-existed in vitro, and that the probability of polarization towards M2 was dose-dependent on IL-10 and independent of IL-12 co-treatment. These data represent the first evidence to date the macrophage polarization is "stochastic" at a coarse-grained level. Heterogeneity was pronounced immediately following activation via LPS and evolved via dynamics that differed based upon cytokine \footnotetext{
Chemical and Biological Engineering, Northwestern University, Evanston, IL,
} USA

C 2013 Chuang and Leonard; licensee BioMed Central Ltd. This is an Open Access article distributed under the terms of the Creative pretreatment. Finally, we investigated macrophage polarization dynamics in vivo. Although conventional wisdom states that macrophages transition from M1 to M2 during tumor progression, this putative transition is poorly understood and sparsely characterized at early stages of tumor development. Therefore, we characterized the dynamics of macrophage polarization during melanoma progression in a syngeneic murine model (B16F0 cells and C57/Bl6 mice). Heterogeneous macrophage polarization was observed at early time points post-tumor implantation, macrophages transitioned from M1 to M2 (systemically and at the tumor) as CD8+ CTL transitioned into regulatory $\mathrm{T}$ cell phenotypes. Such insights reshape our understanding of immune responses and should help to identify novel therapeutic targets and strategies for treating cancer.

Published: 7 November 2013

doi:10.1186/2051-1426-1-S1-P182 macrophage polarization via coupled multicellular networks. Journal for ImmunoTherapy of Cancer 2013 1(Suppl 1):P182.

Submit your next manuscript to BioMed Central and take full advantage of:

- Convenient online submission

- Thorough peer review

- No space constraints or color figure charges

- Immediate publication on acceptance

- Inclusion in PubMed, CAS, Scopus and Google Scholar

- Research which is freely available for redistribution \\ () Biomed Central}

